\title{
Transplant characteristics and self-reported pulmonary outcomes in Swiss childhood cancer survivors after hematopoietic stem cell transplantation-a cohort study
}

\author{
Maria Otth $\mathbb{D}^{1,2,3} \cdot$ Christina Schindera $\mathbb{D}^{1,4} \cdot$ Tayfun Güngör $\mathbb{D}^{5} \cdot$ Marc Ansari ${ }^{6,7} \cdot$ Katrin Scheinemann $\mathbb{D}^{2,8,9}$ •

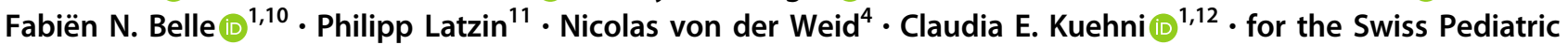 \\ Oncology Group (SPOG)
}

Received: 28 May 2020 / Revised: 16 October 2020 / Accepted: 3 November 2020 / Published online: 25 November 2020

(c) The Author(s) 2020. This article is published with open access

\begin{abstract}
Childhood cancer survivors treated with hematopoietic stem cell transplantation are at high risk for pulmonary morbidity and mortality. In this retrospective study we described transplant characteristics of pediatric patients who underwent hematopoietic stem cell transplantation in Switzerland and how these characteristics changed over time, compared self-reported pulmonary outcomes between transplanted and non-transplanted survivors, and investigated risk factors for the reported pulmonary outcomes. As part of the population-based Swiss Childhood Cancer Survivor Study, we sent questionnaires to all $\geq 5$-year childhood cancer survivors diagnosed 1976-2010 at age $\leq 20$ years. We included 132 transplanted survivors and 368 matched non-transplanted survivors. During the study period transplant characteristics changed, with decreasing use of total body irradiation and increased use of peripheral blood stem cells and mismatched and unrelated donors as transplant source. One-fifth of transplanted survivors $(20 \%, 95 \%$ CI 13-27\%) and 18\% of non-transplanted survivors (95\%CI 13-21\%) reported at least one pulmonary outcome. None of the analyzed factors was significantly associated with an increased risk of pulmonary outcomes in multivariable analysis. We found that pulmonary outcomes were frequently reported in transplanted and nontransplanted childhood cancer survivors, indicating a strong need for long-term pulmonary follow-up care.
\end{abstract}

Members of the Swiss Pediatric Oncology Group (SPOG) are listed below Acknowledgements.

Supplementary information The online version of this article (https:// doi.org/10.1038/s41409-020-01137-1) contains supplementary material, which is available to authorized users.

Claudia E. Kuehni

claudia.kuehni@ispm.unibe.ch

1 Childhood Cancer Research Group, Institute of Social and Preventive Medicine, University of Bern, Bern, Switzerland

2 Division of Oncology-Hematology, Department of Pediatrics, Kantonsspital Aarau, Aarau, Switzerland

3 Graduate School for Cellular and Biomedical Sciences, University of Bern, Bern, Switzerland

4 Division of Hematology and Oncology, University Children's Hospital Basel and University of Basel, Basel, Switzerland

5 Division of Hematology/Oncology/Immunology and SCT, Children's Research Center (CRC), University Children's Hospital Zurich-Eleonore Foundation, Zurich, Switzerland

6 Department of Women, Child and Adolescent, OncologyHematology Unit, Geneva University Hospital,

\section{Introduction}

Hematopoietic stem cell transplantation (HSCT) is an effective but intensive treatment for childhood cancer. HSCT can be performed as allogeneic or autologous

\section{Geneva, Switzerland}

7 CANSEARCH Research Laboratory, Medical Faculty, University of Geneva, Geneva, Switzerland

8 University of Basel, Basel, Switzerland

9 Department of Pediatrics, McMaster University Hamilton, Hamilton, ON, Canada

10 Center for Primary Care and Public Health (Unisanté), University of Lausanne, Lausanne, Switzerland

11 Division of Respiratory Medicine, Department of Pediatrics, Inselspital, University Hospital, University of Bern, Bern, Switzerland

12 Division of Pediatric Hematology/Oncology, Department of Pediatrics, Inselspital, Bern University Hospital, University of Bern, Bern, Switzerland 
transplantation and is used either as first line or salvage treatment [1-4]. The history of allogeneic HSCT goes back to the $1980 \mathrm{~s}$ and indications, conditioning regimens, and donor sources have changed enormously since then $[5,6]$. Pulmonary damage and late effects due to lung toxic treatments and complications prior to, during, or after transplantation can occur in childhood cancer survivors (CCS) [7-9]. Lung toxic treatments include the chemotherapeutics bleomycin, busulfan, carmustine (BCNU) or lomustine (CCNU), radiation involving the lung tissue, total body irradiation (TBI), and thoracic surgery [10-13]. Transplant-specific pulmonary complications include idiopathic pulmonary syndrome and complications from the spectrum of pulmonary graft versus host disease (GvHD), such as bronchiolitis obliterans or bronchiolitis obliterans organizing pneumonia [7, 14-16]. Severe pulmonary infections are additional complications due to long-lasting neutropenic episodes.

Pulmonary symptoms and diseases, summarized as pulmonary outcomes, are associated with high morbidity in survivors [17-19]. Cohort studies showed that survivors more often report pulmonary outcomes than siblings [20, 21]. To date, pulmonary outcomes in survivors after HSCT have only been reported by few single-center studies $[22,23]$. Data based on national population-based assessments of pulmonary outcomes are lacking.

This nationwide retrospective study describes transplant characteristics, such as transplant indications and conditioning regimens, of pediatric patients who had HSCT in Switzerland and how these characteristics changed over time. Then, we compared self-reported pulmonary outcomes between transplanted and nontransplanted survivors and investigated risk factors for reporting pulmonary outcomes.

\section{Methods}

\section{The Swiss Childhood Cancer Survivor Study}

The Swiss Childhood Cancer Survivor Study (SCCSS) is a long-term national cohort study of all patients registered in the Swiss Childhood Cancer Registry (SCCR) who have been diagnosed since 1976, have survived $\geq 5$ years after initial diagnosis, and were alive at the time of study inclusion [24]. The SCCR is a nationwide, population-based cancer registry including all patients diagnosed below age $<21$ years with leukemia, lymphoma, central nervous system (CNS) tumors, malignant solid tumors, or Langerhans cell histiocytosis [25]. From 2007 to 2017, we sent questionnaires to parents of children aged 5-15 years, adolescents aged $16-19$ years, and adult CCS aged $\geq 20$ years. The Ethics Committee of the Canton of Bern approved the SCCR and SCCSS (KEK-BE:
166/2014). The SCCSS is registered at ClinicalTrials.gov (identifier: NCT03297034).

\section{Study population}

We included all survivors who participated in the SCCSS and had been treated in a clinic affiliated to the Swiss Pediatric Oncology Group (SPOG) between 1976 and 2010. As the definition of 5-year survivors was based on the year of diagnosis and not the year of HSCT, some participants might have been transplanted $<5$ years before answering the questionnaire. As comparison group, we included survivors participating in the SCCSS who had not had a HSCT. Nontransplanted CCS were matched to transplanted CCS based on sex, diagnosis, age at diagnosis (range \pm 2 years), and year of diagnosis (range \pm 5 years) striving for a 1:3 ratio. Through this matching we wanted to achieve that CCS in both groups were as similar as possible in terms of sex, age at diagnosis and diagnosis, but did only differ by whether they had had HSCT or not. This matching did probably not eliminate all other differences between the groups since the reason for HSCT, such as high-risk status or relapse, already demands additional treatment for the HSCT patients.

\section{Treatment and transplant characteristics}

We collected treatment- and transplant-related characteristics of transplanted survivors from medical records. We calculated cumulative doses for eight known or suspected lung toxic agents: bleomycin, busulfan, carmustin (BCNU), cyclophosphamide, ifosfamide, lomustin (CCNU), melphalan, and thiotepa $[11-13,26]$. We combined cumulative doses of alkylating agents (all chemotherapeutics except of bleomycin) by calculating the cyclophosphamide equivalent dose (CED) [27]. We categorized the cumulative CED as either lower/equal to or higher than $11,300 \mathrm{mg} / \mathrm{m}^{2}$ with a median-split. We converted busulfan given orally to busulfan intravenously by multiplying it by factor 0.8 [28]. We categorized chest radiation as yes/no according to the Children's Oncology Group guidelines version 5.0 [13] and included irradiation of the upper abdomen. We recorded surgery to the thorax, lung, chest wall, mediastinum, and thoracic spine. Needle biopsies and implantation of venous devices were not coded as thoracic surgery. We collected date of transplantation, history of relapse, remission status, source of transplant, stem cell donor, cytomegalovirus (CMV) status, sex and blood group of donor and recipient, and information on graft versus host disease (GvHD). We categorized stem cell transplantation into autologous and allogeneic and further specified allogeneic transplantation into Human Leucocyte Antigen (HLA) matched (e.g., 12/ 12) and HLA-mismatched (e.g., 9/10) donors. As HLA 
typing and documentation changed substantially in the last decades, it was not possible to assess exact HLA matching $[29,30]$. We categorized GvHD into acute and chronic according to information from medical records.

\section{Pulmonary outcomes}

We collected information on pulmonary symptoms (chronic cough defined as $\geq 3$ months) and diseases (pneumonia in last 2 years, lung fibrosis, emphysema, or chest wall abnormality) from the SCCSS questionnaires. We categorized the different pulmonary outcomes as yes/no (present/absent) variables. In addition to answering the questions, participants could describe other problems as free text. Responses we could not assign to one of the existing categories were coded as "other pulmonary problem". We had $\leq 5 \%$ missings on pulmonary outcomes except for pneumonia (6\% missings). We allocated missing information to "not having the pulmonary outcome" assuming that survivors would mention pulmonary outcomes if they were clinically significant.

\section{Clinical and lifestyle characteristics}

We extracted the following clinical characteristics from the SCCR: sex, age at diagnosis, year of diagnosis, and cancer diagnoses according to the International Classification of Childhood Cancer, $3^{\text {rd }}$ edition [31]. For analyses, we used the following four diagnostic categories: leukemia, where patients with relapsed and refractory disease often receive allogeneic HSCT, lymphoma, and neuroblastoma, where autologous HSCT is used for relapsed or high-risk disease, and other diagnoses, where HSCT is used less frequently. For lifestyle characteristics we extracted smoking status from the questionnaires (Supplementary Explanation E1).

\section{Statistical analysis}

We used descriptive statistics to describe sociodemographic, lifestyle, and clinical characteristics of transplanted and non-transplanted CCS. To assess trends in transplant characteristics across transplant eras we used the "nptrend" command in STATA software [32]. We compared the prevalence of pulmonary outcomes between transplanted and non-transplanted CCS using chi-square tests. We used logistic regression and likelihood ratio tests to quantify associations between sociodemographic, lifestyle, clinical, and transplant-related variables and pulmonary outcomes in transplanted CCS. We retained variables with a $p$ value $\leq 0.1$ in the univariable analysis for inclusion into the multivariable model and included radiotherapy as a priori confounder according to the literature. We compared sociodemographic and clinical characteristics of transplanted CCS who did or did not respond to the questionnaire by using chi-square tests and student's $t$-tests. We used STATA software (Version 16.0, Stata Corporation, Austin, TX) to analyze the data.

\section{Results}

\section{Characteristics of study population}

We included 132 transplanted and 368 matched nontransplanted CCS (Supplementary Figs. F1 and F2). Transplanted responders and non-responders did not differ in sociodemographic, lifestyle, and clinical characteristics (Supplementary Table S1). The median age of transplanted CCS was 6.5 years (interquartile range, IQR 2.9-11.6 years) at cancer diagnosis and 8.8 years (IQR 4.8-13.6) at transplantation. Median follow-up time was 9.8 years (IQR 7.2-15.9). Leukemia was the most frequent cancer diagnosis $(55 \%)$, followed by lymphoma $(15 \%)$, and neuroblastoma (14\%) (Table 1).

\section{Transplant characteristics and change over time}

The absolute number of transplanted CCS who participated in the SCCSS increased over time. Leukemia remained the most common underlying cancer diagnosis in all three eras (Table 2). Conditioning regimens changed with a relative but non-significant reduction in TBI-containing regimens from $61 \%$ in the first to $39 \%$ in the other two eras ( $p$ for trend $=$ 0.083). Among chemotherapeutics, the proportion of CCS who received ifosfamide increased $(p=0.002)$ but the median cumulative dose decreased non-significantly $(p=0.477)$. Also cyclophosphamide dosage decreased $(p<0.001)$ with no significant reduction in the proportion of CCS receiving it $(p=0.186)$. For bleomycin there was a trend towards lower cumulative doses in more recent eras $(p=0.094)$. Two-thirds (65\%) of CCS had radiotherapy involving the thorax with no significant change over time, and 9\% had thoracic surgery with a trend to an increasing proportion of CCS in more recent years. Nearly half of transplanted CCS received autologous HSCT (46\%) and in 57\% HSCT was performed in first remission or refractory disease. The proportion of transplanted CCS receiving peripheral blood stem cells increased from $27 \%$ to $71 \%$ with a corresponding reduction in the proportion of those receiving bone marrow stem cells ( $p$ for trend <0.001). Eight CCS developed chronic GvHD (cGvHD) but none had pulmonary GvHD (Supplementary Table S2). Supplementary Tables S2 and S3 provide summaries of clinical, treatment, and transplant characteristics for CCS transplanted in autologous or allogeneic settings, stratified by era of transplantation. Differences in CCS exposed to allogeneic or autologous HSCT are shown in Supplementary Table S4. 
Table 1 Characteristics of transplanted $(N=132)$ and nontransplanted $(N=368)$ childhood cancer survivors, matched by sex, age at diagnosis, diagnosis, and year of diagnosis (1:3 ratio).

$\begin{array}{ll}\begin{array}{l}\text { Transplanted CCS } \\ (n=132)\end{array} & \begin{array}{l}\text { Non-transplanted } \\ \text { CCS }(n=368)\end{array} \\ n(\%) & n(\%)\end{array}$

Sociodemographic and lifestyle characteristics

\begin{tabular}{|c|c|c|}
\hline Sex, male & $69(52)$ & $195(53)$ \\
\hline $\begin{array}{l}\text { Age at questionnaire, } \\
\text { median years (IQR) }\end{array}$ & $18.4(13.8-22.9)$ & $18.5(13.6-23.8)$ \\
\hline \multicolumn{3}{|l|}{ Smoking status ${ }^{\mathrm{a}}$} \\
\hline Active smoking & $7(5)$ & $27(7)$ \\
\hline Passive smoking & $63(48)$ & $163(44)$ \\
\hline Former active smoking & $9(6)$ & $20(6)$ \\
\hline Never smoking & $54(41)$ & $158(43)$ \\
\hline \multicolumn{3}{|l|}{ Clinical characteristics } \\
\hline $\begin{array}{l}\text { Age at diagnosis, median } \\
\text { years (IQR) }\end{array}$ & $6.5(2.9-11.6)$ & $6.4(2.7-11.4)$ \\
\hline $\begin{array}{l}\text { Age at transplantation, } \\
\text { median years (IQR) }\end{array}$ & $8.8(4.8-13.6)$ & NA \\
\hline $\begin{array}{l}\text { Follow-up time }{ }^{\mathrm{b}} \text {, median } \\
\text { years (IQR) }\end{array}$ & $9.8(7.2-15.9)$ & $10.1(7.9-15.1)$ \\
\hline \multicolumn{3}{|l|}{ Era of diagnosis } \\
\hline $1976-1995$ & $40(30)$ & $120(33)$ \\
\hline $1996-2005$ & $60(45)$ & $156(42)$ \\
\hline $2006-2010$ & $32(25)$ & $92(25)$ \\
\hline \multicolumn{3}{|c|}{ Childhood cancer diagnosis according to ICCC-3 } \\
\hline I: Leukemia & $72(55)$ & $214(58)$ \\
\hline II: Lymphoma & $20(15)$ & $60(16)$ \\
\hline IV: Neuroblastoma & $19(14)$ & $44(12)$ \\
\hline Other $^{\mathrm{c}}$ & $21(16)$ & $50(14)$ \\
\hline
\end{tabular}

$C C S$ childhood cancer survivors, ICCC-3 International Classification of Childhood Cancer, 3rd edition, $I Q R$ interquartile range.

a“Active" and "former active smoking" assessed in adolescents and adults; "passive smoking" in children corresponds to having parents who currently smoke or formerly smoked, "never smoking" in children corresponds to having both parents who never smoked.

${ }^{\mathrm{b}}$ Time from first diagnosis until date of answering the questionnaire.

${ }^{c}$ Other tumors in transplanted survivors include: tumors of the central nervous system $(n=6)$, retinoblastoma $(n=1)$, malignant bone tumors $(n=7)$, soft tissue sarcomas $(n=4)$, malignant germ cell tumors $(n=3)$ Other tumors in non-transplanted survivors include: tumors of the central nervous system $(n=12)$, retinoblastoma $(n=1)$, malignant bone tumors $(n=9)$, soft tissue sarcomas $(n=4)$, malignant germ cell tumors $(n=3)$.

\section{Prevalence of pulmonary outcomes}

Any pulmonary outcome was reported as often in transplanted $(20 \%)$ as in non-transplanted CCS $(18 \% ; p=$ 0.507). The occurrence of the listed pulmonary outcomes was not significantly different between transplanted and non-transplanted CCS. Pneumonia was the most frequently reported outcome (Fig. 1). The proportion of transplanted CCS reporting any pulmonary outcome did not change by era of transplantation (Table 2).

\section{Risk factors for pulmonary outcomes}

In univariable logistic regression analysis, we found associations between older age at cancer diagnosis (increase per year; odds ratio $[\mathrm{OR}] 1.2,95 \%$ confidence interval [CI] 1.05-1.28), exposure to bleomycin (OR 4.63, 95\%CI 1.08-19.97), and thoracic surgery (OR 7.44, 95\%CI 2.13-25.92) with any pulmonary outcome (Table 3). We found no significant association with era of diagnosis, treatment with other chemotherapeutics, median CED, and thoracic radiotherapy, but numbers were small. Transplantrelated factors were also not significantly associated with reporting of pulmonary outcomes (Table 3). In multivariable logistic regression analysis, the effect of thoracic surgery was reduced to an OR of 3.91 (95\%CI 0.95-16.02), suggesting that it has been confounded by other factors related to disease and treatment (Table 4). Most of the 12 CCS treated with thoracic surgery have been diagnosed with Ewing sarcoma $(n=7)$ or lymphoma $(n=4)$. All except one CCS have been transplanted autologous, most suffered from relapsed disease $(n=10)$, received radiotherapy to the chest $(n=10)$, were treated with open thoracic surgeries $(n=9)$, received at least one lung toxic chemotherapeutic agent $(n=7)$, or have been exposed to a combination of radiotherapy and thoracic surgery or resection of lung tissue $(n=9)$ (Supplementary Table S5).

\section{Discussion}

This nationwide population-based cohort study found that transplant characteristics changed over time with fewer HSCT recipients receiving TBI or lung toxic chemotherapeutics. One-fifth of $\geq 5$-year CCS reported at least one pulmonary outcome 10 years after cancer diagnosis irrespective of whether they had been transplanted or not. Our analyses point to older age at diagnosis and thoracic surgery as possible risk factors for self-reported pulmonary outcomes.

TBI is a crucial component of conditioning regimens for allogeneic HSCT, but known to be lung toxic. Even though TBI cannot completely be replaced by chemotherapy, such as in acute lymphoblastic leukemia [33], we found that the use of TBI has become less common in more recent eras. There was a non-significant trend towards lower cumulative doses of bleomycin and we found no evidence for a change in cumulative doses of carmustine, but numbers were small. The increasing use of peripheral blood stem cells in more recent eras is in line with literature [34-36] and the 
Table 2 Characteristics of transplanted childhood cancer survivors $(N=132)$ stratified by era of transplantation.

$\begin{array}{lllll}\text { Total } & 1976-1995 & 1996-2005 & 2006-2015 & p \text { value* } \\ (n=132) & (n=33) & (n=51) & (n=48) & \\ n(\%) & n(\%) & n(\%) & n(\%) & \end{array}$

\section{Clinical characteristics}

Cancer diagnosis according to ICCC-3

\section{I: Leukemia \\ II: Lymphoma \\ IV: Neuroblastoma \\ Other $^{\mathrm{a}}$ \\ Treatment characteristics}

Conditioning containing

TBI

Conditioning regimens

$$
\begin{aligned}
& \text { TBI }+ \\
& \text { cyclophosphamide } \\
& \pm \text { others }
\end{aligned}
$$

TBI + others

Busulfan +

cyclophosphamide

\pm other

$$
\text { Busulfan } \pm \text { others }
$$

Carmustine \pm others

Cyclophosphamide

\pm others

\section{Melphalan \pm}

carboplatin \pm others

$n(\%)$

$n(\%)$

$n(\%)$

Chemotherapeutic agents

Alkylating agents
combined $^{\mathrm{b}}$
Busulfan
Carmustine
Cyclophosphamide
Ifosfamide
Lomustine
Melphalan
Thiotepa
Bleomycin

Chemotherapeutic agents, $\mathrm{mg} / \mathrm{m}^{2}$

$\begin{array}{ll}\begin{array}{l}\text { Alkylating agents } \\ \text { combined }^{\mathrm{b}}\end{array} & 11329 \\ \text { Busulfan } & \\ \text { Carmustine } & 443(324-480) \\ \text { Cyclophosphamide } & 300(298-300) \\ & 4200 \\ \text { Ifosfamide } & (3021-7535) \\ & 9941 \\ \text { Lomustine } & (4032-22500) \\ \text { Melphalan } & 395(190-600) \\ \text { Thiotepa } & 140(139-169) \\ \text { Bleomycin } & 680(588-900) \\ & 40(40-46)\end{array}$

$72(55)$
$20(15)$
$19(14)$
$21(16)$

$59(45)$

$18(55)$
$8(24)$
$5(15)$
$2(6)$

$20(61)$

$16(48)$

4 (12)

25 (19)

$28(21)$

7 (21)

8 (6)

1 (3)

3 (9)

$9(7)$

19 (14)

1 (3)

$1(3)$

131 (99)

37 (28)

9 (7)

123 (93)

62 (47)

2 (2)

44 (33)

14 (11)

8 (6)

(IQR)

40 (40-46)

$\begin{array}{ll}33(100) & 50(98) \\ 9(27) & 16(31) \\ 4(12) & 3(6) \\ 33(100) & 46(90) \\ 9(27) & 23(45) \\ 1(3) & - \\ 9(27) & 17(33) \\ 3(9) & 8(16) \\ 3(9) & 3(6) \\ & \\ 11658 & 11367 \\ (7924-17391) & (5879-21425) \\ 480(470-587) & 344(297-480) \\ 300(298-351) & 300(298-300) \\ 7299 & 4247 \\ (4200-8684) & (3090-8230) \\ 11500 & 10227 \\ (5200-16032) & (4032-22500) \\ 190 & - \\ 140(140-142) & 140(140-140) \\ 750(168-900) & 749(591-900) \\ 42(40-80) & 40(40-50) \\ & \end{array}$

0.806

28 (58)

5 (10)

6 (13)

9 (19)

19 (39)

0.083

0.003

6 (13)

13 (27)

10 (21)

11 (21)

3 (6)

3 (6)

2 (4)

11 (23)

7 (14)

48 (100)

12 (25)

0.776

2 (4)

0.180

44 (92)

0.186

30 (63)

0.002

1 (2)

0.835

18 (38)

0.342

3 (6)

0.563

2 (4)

0.371

8546

(4447-16131)

$440(374-449) \quad 0.021$

$300(291-306) \quad 0.737$

3439

$<0.001$

(2634-5258)

8181

0.477

(4017-19767)

600

0.317

140 (139-180) $\quad 0.739$

610 (307-900) 0.921

$30(20-40) \quad 0.094$ 
Table 2 (continued)

\begin{tabular}{|c|c|c|c|c|c|}
\hline & $\begin{array}{l}\text { Total } \\
(n=132) \\
n(\%)\end{array}$ & $\begin{array}{l}1976-1995 \\
(n=33) \\
n(\%)\end{array}$ & $\begin{array}{l}1996-2005 \\
(n=51) \\
n(\%)\end{array}$ & $\begin{array}{l}2006-2015 \\
(n=48) \\
n(\%)\end{array}$ & $p$ value* \\
\hline $\begin{array}{l}\text { Radiotherapy involving } \\
\text { the thorax }{ }^{c}\end{array}$ & $86(65)$ & $25(76)$ & $32(63)$ & $29(60)$ & 0.175 \\
\hline Thoracic surgery ${ }^{\mathrm{d}}$ & $12(9)$ & $1(3)$ & $5(10)$ & $6(13)$ & 0.157 \\
\hline \multicolumn{6}{|l|}{ Transplant characteristics } \\
\hline \multicolumn{5}{|c|}{ Remission status at transplantation } & 0.906 \\
\hline First remission & $75(57)$ & $16(48)$ & $35(69)$ & $24(50)$ & \\
\hline Relapsed disease & $57(43)$ & $17(52)$ & $16(31)$ & $24(50)$ & \\
\hline \multicolumn{5}{|l|}{ Stem cell donor } & 0.098 \\
\hline Autologous & $61(46)$ & $17(52)$ & $25(49)$ & $19(39)$ & \\
\hline $\begin{array}{l}\text { HLA identical sibling / } \\
\text { HLA matched (un-) } \\
\text { relative donor }\end{array}$ & $56(42)$ & $16(48)$ & $19(37)$ & $21(44)$ & \\
\hline $\begin{array}{l}\text { HLA mismatch (un-) } \\
\text { related /haploidentical }\end{array}$ & $15(11)$ & 0 & $7(14)$ & $8(17)$ & \\
\hline \multicolumn{5}{|l|}{ Source of transplant } & $<0.001$ \\
\hline Cord blood & $6(5)$ & - & $1(2)$ & $5(10)$ & \\
\hline Peripheral blood & $75(57)$ & $9(27)$ & $32(63)$ & $34(71)$ & \\
\hline Bone marrow & $46(35)$ & $22(67)$ & $17(33)$ & $7(15)$ & \\
\hline Unknown & $5(4)$ & $2(6)$ & $1(2)$ & $2(4)$ & \\
\hline Pulmonary outcome & $26(20)$ & $7(21)$ & $11(22)$ & $8(17)$ & 0.582 \\
\hline
\end{tabular}

HLA human leukocyte antigen, ICCC-3 International Classification of Childhood Cancer, 3rd edition, IQR interquartile range, $N$ number, $T B I$ total body irradiation.

* $p$ value for trend.

${ }^{a}$ Other tumors include: tumors of the central nervous system $(n=6)$, retinoblastoma $(n=1)$, malignant bone tumors $(n=7)$, soft tissue sarcoma $(n=4)$, malignant germ cell tumors $(n=3)$.

${ }^{\mathrm{b}}$ Combination according to Cyclophosphamide Equivalent Dose (CED) [27].

${ }^{\mathrm{c}}$ Thoracic radiation fields according to COG guidelines, Version 4.0, Oct 2018, including radiation to the chest, whole lung, mediastinum, (mini-) mantle field, TBI and additionally upper abdomen and thoracic spine, including craniospinal irradiation.

${ }^{\mathrm{d}}$ Thoracic surgery according to COG guidelines, Version 4.0, Oct 2018, including thoracotomy, chest wall surgery, rib resection, lobectomy, pulmonary metastasectomy and wedge resection.

increasing use of mismatched (un-) related donors reflects the overall progress in HSCT over time.

The proportion of transplanted CCS reporting any pulmonary outcome did not change during the three HSCT eras. Studies that compared self-reported pulmonary outcomes in transplanted CCS are few. Fanfulla et al. examined children during the first 18 months after allogeneic HSCT [22]. Cough was reported by $15-25 \%$ of children and pneumonia was diagnosed in the first 6 months in $19 \%$ of children. The occurrence of pneumonia in the first 6 months, is indicative of delayed immune reconstitution rather than late pulmonary outcomes. Since the follow-up (18 months) is shorter than in our population (10 years) direct comparison is difficult. Also in the entire cohort of Swiss CCS ( $N=1894)$ pneumonia was the most frequently reported pulmonary outcome (10\%), and pulmonary fibrosis $(0.8 \%)$ and emphysema $(0.2 \%)$ were reported by few CCS [20]. CCS in the North American Childhood Cancer Survivor Study showed a different distribution of pulmonary outcomes with chronic cough being the most frequent outcome $(7.8 \%)$, followed by pulmonary fibrosis $(1.9 \%)$, and recurrent pneumonia $(1.7 \%)$ [21]. We found no difference in the prevalence of pulmonary outcomes between transplanted and non-transplanted CCS in our study $(20 \%$ vs. $18 \%$ ). This could be explained by the high proportion of leukemia (58\%) and lymphoma (16\%) diagnoses in nontransplanted CCS due to the matching. A Danish cohort study included 94 leukemia survivors a median of 10 years from diagnosis, treated with chemotherapy only, and $11 \%$ suffered from pulmonary problems, mainly cough [37]. A 
Fig. 1 Prevalence of selfreported pulmonary diseases and symptoms in transplanted $(N=132)$ and non-

transplanted matched childhood cancer survivors $(N$ $=368$ ). Error bars represent 95\% confidence intervals. $P$ value comparing prevalence between transplanted and nontransplanted survivors. *Total $\mathrm{N}$ reduced for pulmonary fibrosis and emphysema because question only asked in adolescents and adults: $N=85$ transplanted survivors, $N=195$ non-transplanted survivors. ** "Other pulmonary outcome" includes reduced lung function $(n=3)$ and pulmonary GvHD $(n=1)$.

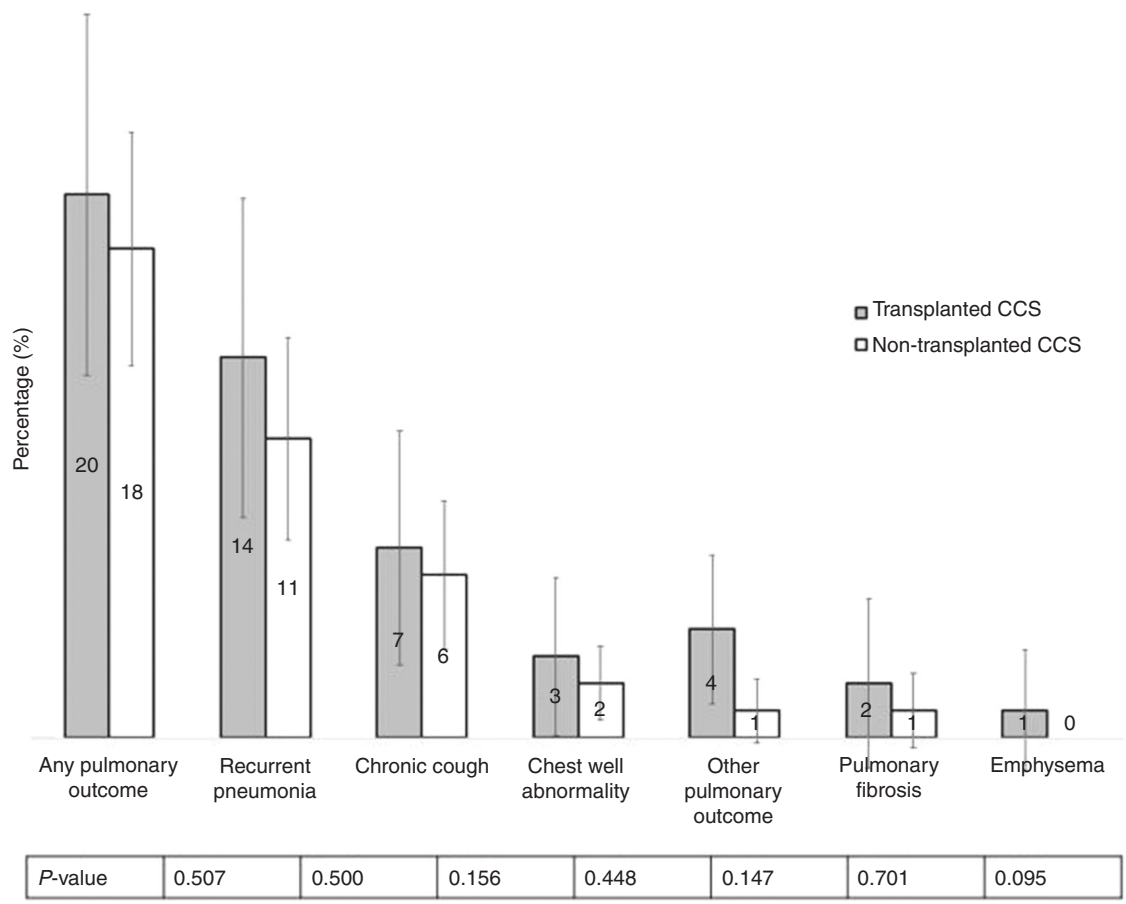

US study including Hodgkin's lymphoma survivors treated with chest radiation but without HSCT showed that $17 \%$ had at least one episode of pneumonia and 9\% reported dyspnea [38].

CCS who had undergone thoracic surgery in addition to HSCT reported more pulmonary outcomes than those without thoracic surgery. This might be because this group of CCS had received more often thoracic radiotherapy or lung toxic chemotherapeutics, had more often been diagnosed with relapsed disease, and underwent open thoracic surgeries in most cases, which goes along with a more intensive treatment. Residual confounding by these additional lung toxic treatment modalities probably leads to an overestimation of the association between thoracic surgery and pulmonary outcomes. Older age at diagnosis, resulting in older age at HSCT, was another risk factor for pulmonary outcomes in univariable analysis. No study has assessed self-reported pulmonary outcomes in the context of age at HSCT, but four studies showed an association between older age at HSCT and deterioration in selected pulmonary function parameters [23, 39-41]. In multivariable analysis, bleomycin was not a risk factor for pulmonary outcomes anymore, which is in line with findings from the whole Swiss CCS cohort [20]. In our cohort, we found no significant effect of other selected chemotherapeutics and transplant-related factors on the reporting of pulmonary outcomes. All studies that evaluated the impact of cGvHD on the lung, used pulmonary function tests as outcome measure [41-44]. They reported a negative effect of cGvHD on pulmonary function. We explain the missing effect of cGvHD, lomustine, and carmustine by the low number of survivors exposed to each of these factors. Also some CCS with severe pulmonary cGvHD might have died before receiving the SCCSS questionnaire and missing or nondetailed documentation in the medical records might have led to an underestimation of the effect of cGvHD on pulmonary outcomes.

We found no difference in pulmonary outcomes between CCS treated with autologous and allogeneic HSCT. Thoracic surgery was overrepresented in the autologous group because of the underlying diagnoses, mainly bone tumors. In contrast, CCS treated with allogeneic HSCT were more often exposed to chest radiotherapy, which can lead to radiation pneumonitis and an increased risk of interstitial pneumonitis due to infections such as CMV. Both factors have not been assessed in detail.

The strengths of this study include the population-based national design of the SCCSS, the high response rate of transplanted CCS (71\%), and the comparability between responding and nonresponding transplanted survivors. This makes us confident, that our results can be extrapolated to $\geq 5$-year Swiss survivors who underwent HSCT. In addition, the completeness of exact treatment exposure, including cumulative doses of chemotherapeutics and detailed information on HSCT in transplanted CCS is another strength.

The reliance on self-reported outcome data is a limitation and our study did not include objective pulmonary function 
Table 3 Association between sociodemographic, clinical, treatment, and transplant characteristics on self-reported pulmonary outcomes.

\begin{tabular}{|c|c|c|c|c|c|c|}
\hline & \multicolumn{3}{|c|}{ Reporting of any pulmonary outcome } & \multirow[b]{2}{*}{ OR } & \multirow[b]{2}{*}{$95 \% \mathrm{CI}$} & \multirow[b]{2}{*}{$p$ value* } \\
\hline & $n_{\text {outcome }}$ & $N_{\text {total }}$ & $\%$ & & & \\
\hline \multicolumn{7}{|c|}{ Sociodemographic and lifestyle characteristics } \\
\hline Sex & & & & & & 0.795 \\
\hline Male & 13 & 69 & 19 & 1 & & \\
\hline Female & 13 & 63 & 21 & 1.12 & $0.47-2.64$ & \\
\hline Age at questionnaire, continuous (years) & 26 & 132 & 20 & 1.05 & $0.99-1.11$ & 0.088 \\
\hline Smoking status ${ }^{\mathrm{a}}$ & & & & & & 0.924 \\
\hline Never smoking & 12 & 60 & 20 & 1 & & \\
\hline Passive smoking & 10 & 56 & 18 & 0.87 & $0.34-2.21$ & \\
\hline Former active smoking & 2 & 9 & 22 & 1.14 & $0.21-6.21$ & \\
\hline Active smoking & 2 & 7 & 29 & 1.60 & $0.27-9.28$ & \\
\hline \multicolumn{7}{|l|}{ Clinical characteristics } \\
\hline Age at diagnosis, continuous (years) & 26 & 132 & 20 & 1.2 & $1.05-1.28$ & 0.002 \\
\hline Follow-up time, continuous (years) & 26 & 132 & 20 & 0.98 & $0.91-1.06$ & 0.613 \\
\hline Era of diagnosis & & & & & & 0.800 \\
\hline 1976-1990 & 5 & 20 & 25 & 1 & & \\
\hline 1991-2000 & 8 & 45 & 18 & 0.64 & $0.18-2.31$ & \\
\hline 2001-2010 & 13 & 67 & 19 & 0.72 & $0.22-2.35$ & \\
\hline Cancer diagnosis according to ICCC-3 & & & & & & 0.271 \\
\hline Leukemia & 15 & 72 & 21 & 1 & & \\
\hline Lymphoma & 5 & 20 & 25 & 1.27 & $0.39-4.04$ & \\
\hline Neuroblastoma & 1 & 19 & 5 & 0.21 & $0.03-1.71$ & \\
\hline Other $^{b}$ & 5 & 21 & 24 & 1.18 & $0.37-3.76$ & \\
\hline \multicolumn{7}{|l|}{ Treatment characteristics } \\
\hline Bleomycin & & & & & & 0.040 \\
\hline No & 22 & 124 & 18 & 1 & & \\
\hline Yes & 4 & 8 & 50 & 4.63 & $1.08-19.97$ & \\
\hline Busulfan & & & & & & 0.190 \\
\hline No & 16 & 95 & 17 & 1 & & \\
\hline Yes & 10 & 37 & 27 & 1.83 & $0.74-4.51$ & \\
\hline Nitrosureas (BCNU and CCNU) & & & & & & 0.107 \\
\hline No & 22 & 122 & 18 & 1 & & \\
\hline Yes & 4 & 10 & 40 & 3.03 & $0.79-11.65$ & \\
\hline Cyclophosphamide & & & & & & 0.844 \\
\hline No & 2 & 9 & 22 & 1 & & \\
\hline Yes & 24 & 123 & 20 & 0.84 & $0.16-4.34$ & \\
\hline Ifosfamide & & & & & & 0.596 \\
\hline No & 15 & 70 & 21 & 1 & & \\
\hline Yes & 11 & 62 & 18 & 0.79 & $0.33-1.88$ & \\
\hline Melphalan & & & & & & 0.281 \\
\hline No & 15 & 88 & 17 & 1 & & \\
\hline Yes & 11 & 44 & 25 & 1.62 & $0.67-3.91$ & \\
\hline Treosulfan & & & & & & 0.400 \\
\hline No & 24 & 126 & 19 & 1 & & \\
\hline Yes & 2 & 6 & 33 & 2.12 & $0.36-12.28$ & \\
\hline Alkylating agents ${ }^{\mathrm{c}}$ & & & & & & 0.084 \\
\hline$\leq 11,300 \mathrm{mg} / \mathrm{m}^{2}$ & 9 & 66 & 14 & 1 & & \\
\hline$>11,300 \mathrm{mg} / \mathrm{m}^{2}$ & 17 & 66 & 26 & 2.19 & $0.89-5.37$ & \\
\hline Radiotherapy to chest (including TBI) & & & & & & 0.165 \\
\hline No & 6 & 46 & 13 & 1 & & \\
\hline Yes & 20 & 86 & 23 & 2.02 & $0.75-5.45$ & \\
\hline Thoracic surgery & & & & & & $<0.001$ \\
\hline No & 19 & 120 & 16 & 1 & & \\
\hline Yes & 7 & 12 & 58 & 7.44 & $2.13-25.92$ & \\
\hline
\end{tabular}


Table 3 (continued)

\begin{tabular}{|c|c|c|c|c|c|c|}
\hline & \multicolumn{3}{|c|}{ Reporting of any pulmonary outcome } & \multirow[b]{2}{*}{ OR } & \multirow[b]{2}{*}{$95 \% \mathrm{CI}$} & \multirow[b]{2}{*}{$p$ value* } \\
\hline & $n_{\text {outcome }}$ & $N_{\text {total }}$ & $\%$ & & & \\
\hline \multicolumn{7}{|l|}{ Transplant characteristics } \\
\hline Remission status at transplantation & & & & & & 0.223 \\
\hline First remission/primary refractory & 12 & 75 & 16 & 1 & & \\
\hline Relapsed disease & 14 & 57 & 24 & 1.71 & $0.72-4.05$ & \\
\hline Type of transplantation & & & & & & 0.995 \\
\hline Allogeneic & 14 & 71 & 20 & 1 & & \\
\hline Autologous & 12 & 61 & 20 & 0.99 & $0.42-2.35$ & \\
\hline Stem cell donor & & & & & & 0.739 \\
\hline Autologous & 12 & 61 & 20 & 1 & & \\
\hline HLA ident. sibling, matched (un)related donor & 11 & 56 & 20 & 0.99 & $0.40-2.48$ & \\
\hline HLA mismatched (un)related, haploidentical & 3 & 15 & 20 & 1.02 & $0.25-4.19$ & \\
\hline Source of transplant $(n=66)^{\mathrm{d}}$ & & & & & & 0.933 \\
\hline Bone marrow & 7 & 34 & 21 & 1 & & \\
\hline Peripheral blood & 6 & 26 & 23 & 1.15 & $0.34-3.98$ & \\
\hline Cord blood & 1 & 6 & 17 & 0.77 & $0.08-7.71$ & \\
\hline Graft versus host disease $(n=71)^{\mathrm{d}}$ & & & & & & 0.449 \\
\hline No & 4 & 15 & 27 & 1 & & \\
\hline Yes & 10 & 56 & 18 & 0.59 & $0.16-2.27$ & \\
\hline
\end{tabular}

Results from univariable logistic regression analysis. $N=132$, median age at study 18.4 years.

$B C N U$ Lomustine, $C C N U$ Carmustine, HLA human leukocyte antigen, ICCC-3 International Classification of Childhood Cancer, 3rd edition, OR Odds ratio, $T B I$ total body irradiation, $C I$ confidence interval.

* $p$ value calculate by logistic regression (Wald test) for continuous and binary independent variables and by likelihood ratio test for independent variables with $>2$ categories.

${ }^{a}$ Active and former active smoking assessed in adolescents and adults. Passive and never smoking assessed in children, adolescent and adults.

${ }^{b}$ Other diagnostic groups include: malignant bone tumors $(n=7)$, tumors of the central nervous system $(n=6)$, soft tissue sarcomas $(n=4)$, germ cell tumors $(n=3)$, retinoblastoma $(n=1)$.

${ }^{c}$ Cumulative alkylating dose according to cyclophosphamide equivalent dose (CED); categorized in smaller or equal to the median or larger as the median cumulative dose.

${ }^{\mathrm{d}}$ In survivors undergone allogeneic transplantation only.

tests. CCS treated with open thoracic surgery are reminded by the scar of their history and thus may be more sensitive in dealing with their lung health, and may remember and report pulmonary outcomes better. However, Louie et al. reported a high agreement between self-reported pulmonary outcomes, such as chronic cough, pulmonary fibrosis, and emphysema, and their validation by extractions from medical records (sensitivity 96.2\%; specificity 90.8\%) [45]. The SCCSS has not been designed for survivors after HSCT specifically, neither for the assessment of pulmonary outcomes only and did not include specific questions on exertion-induced dyspnea or effort intolerance. This might have led to underreporting of pulmonary outcomes in our study. Also "pneumonia" might have been misunderstood by lay persons, as it was not defined in the questionnaire. Survival bias due to inclusion of $\geq 5$-year survivors could have led to underestimation of pulmonary outcomes as more severely affected patients might have died. The small number of transplanted CCS who have been exposed to specific chemotherapeutics and transplant-related exposures did not allow for a multivariable analysis of all exposures in a single model. Also the detailed information on treatment exposures, such as cumulative doses, was only available for transplanted CCS. Finally, the absolute numbers of CCS reporting pulmonary outcomes was small, because the study population was young with a relatively short follow-up time, and the incidence of pulmonary outcomes increases over lifetime [20, 21, 39, 46].

In summary, we found that one-fifth of CCS, including those who underwent HSCT and matched controls, developed long-term pulmonary outcomes. As we only assessed self-reported outcomes, using a limited number of questions, this proportion probably only represents the tip of the iceberg. This underlines that we should implement long-term pulmonary follow-up recommendations on a large scale [13, 47-49] using sensitive outcome measures, such as lung function tests, to assess the full spectrum of long-term pulmonary sequelae after childhood cancer at an early stage. 
Table 4 Association between sociodemographic, clinical, treatment, and transplant characteristics on self-reported pulmonary outcomes.

\begin{tabular}{llll}
\hline & OR & $95 \%$ CI & $p$ value \\
\hline Age at diagnosis & 1.13 & $0.99-1.28$ & 0.055 \\
Age at questionnaire & 1.00 & $0.91-1.08$ & 0.892 \\
Bleomycin exposure & 1.57 & $0.28-8.81$ & 0.608 \\
Median CED dose $>11,300 \mathrm{mg} / \mathrm{m}^{2}$ & 1.74 & $0.57-5.33$ & 0.330 \\
Thoracic surgery & 3.91 & $0.95-16.02$ & 0.058 \\
Thoracic radiotherapy & 1.58 & $0.49-5.14$ & 0.446
\end{tabular}

Results from multivariable logistic regression analysis, adjusted for all factors in the table. $N=132$, median 18.4 years at study.

$C E D$ cyclophosphamide equivalent dose, $C I$ confidence interval, $O R$ Odds ratio.

Acknowledgements We thank all childhood cancer patients and families for participating in our survey. We thank the study team of the SCCR (Luzius Mader, Sven Strebel, Nicolas Waespe), Marcel Zwahlen for statistical support, the data managers of the SPOG (Claudia Althaus, Nadine Assbichler, Pamela Balestra, Heike Baumeler, Nadine Beusch, Sarah Blanc, Susann Drerup, Janine Garibay, Franziska Hochreutener, Monika Imbach, Friedgard Julmy, Eléna Lemmel, Rodolfo Lo Piccolo, Heike Markiewicz, Veneranda Mattielo, Annette Reinberg, Renate Siegenthaler, Astrid Schiltknecht, Beate Schwenke, and Verena Stahel) and the data managers and administrative staff of the SCCR (Meltem Altun, Erika Brantschen, Katharina Flandera, Elisabeth Kiraly, Nadine Lötscher, Verena Pfeiffer, Shelagh Redmond, Julia Ruppel, and Ursina Roder). This study is supported by Swiss Cancer League (KLS-3886-02-2016), Swiss Cancer Research (KFS-4157-02-2017 and KFS-4722-02-2019), and Lung League Bern.

The Swiss Pediatric Oncology Group (SPOG) M. Ansari ${ }^{6,7}$, M. Beck Popovic $^{13}$, J. P. Bourquin ${ }^{14}$, P. Brazzola ${ }^{15}$, J. Greiner ${ }^{16}$, J. Rössler ${ }^{12}$, F. Schilling ${ }^{17}$, K. Scheinemann ${ }^{2,8,9}$, N. von der Weid $^{4}$

${ }^{13}$ Pediatric Hematology-Oncology Unit, Lausanne University Hospital, Centre Hospitalier Universitaire Vaudois, Lausanne, Switzerland;

${ }^{14}$ Division of Oncology, University Children's Hospital ZurichEleonore Foundation, Zurich, Switzerland; ${ }^{15}$ Pediatria Bellinzona, Ospedale Regionale di Bellinzona e Valli, Bellinzona, Switzerland; ${ }^{16}$ Division of Hematology and Oncology, Children's Hospital of Eastern Switzerland, St. Gallen, Switzerland; ${ }^{17}$ Division of Oncology/ Hematology, Department of Pediatrics, Kantonsspital Luzern, Lucerne, Switzerland

Funding Open access funding provided by University of Bern.

\section{Compliance with ethical standards}

Conflict of interest The authors declare that they have no conflict of interest.

Publisher's note Springer Nature remains neutral with regard to jurisdictional claims in published maps and institutional affiliations.

Open Access This article is licensed under a Creative Commons Attribution 4.0 International License, which permits use, sharing, adaptation, distribution and reproduction in any medium or format, as long as you give appropriate credit to the original author(s) and the source, provide a link to the Creative Commons license, and indicate if changes were made. The images or other third party material in this article are included in the article's Creative Commons license, unless indicated otherwise in a credit line to the material. If material is not included in the article's Creative Commons license and your intended use is not permitted by statutory regulation or exceeds the permitted use, you will need to obtain permission directly from the copyright holder. To view a copy of this license, visit http://creativecommons. org/licenses/by/4.0/.

\section{References}

1. Merli P, Algeri M, Del Bufalo F, Locatelli F. Hematopoietic stem cell transplantation in pediatric acute lymphoblastic leukemia. Curr Hematologic Malignancy Rep. 2019;14:94-105.

2. Yalcin B, Kremer LC, van Dalen EC. High-dose chemotherapy and autologous haematopoietic stem cell rescue for children with high-risk neuroblastoma. Cochrane Database Syst Rev. 2015: Cd006301.

3. Guerra JA, Dhall G, Marachelian A, Castillo E, Malvar J, Wong $\mathrm{K}$, et al. Marrow-ablative chemotherapy followed by tandem autologous hematopoietic cell transplantation in pediatric patients with malignant brain tumors. Bone Marrow Transplant. 2017;52: 1543-8.

4. Shankar A, Hayward J, Kirkwood A, McCarthy K, Hewitt M, Morland B, et al. Treatment outcome in children and adolescents with relapsed Hodgkin lymphoma-results of the UK HD3 relapse treatment strategy. Br J Haematol. 2014;165: 534-44.

5. Niethammer D, Bader P, Handgretinger R, Klingebiel T. Stem cell transplantation. Klinische Padiatrie. 2013;225(Suppl 1):S94-8.

6. Dopfer R, Henze G, Bender-Gotze C, Ebell W, Ehninger G, Friedrich $\mathrm{W}$, et al. Allogeneic bone marrow transplantation for childhood acute lymphoblastic leukemia in second remission after intensive primary and relapse therapy according to the BFM- and CoALL-protocols: results of the German Cooperative Study. Blood. 1991;78:2780-4.

7. Diab M, ZazaDitYafawi J, Soubani AO. Major pulmonary complications after hematopoietic stem cell transplant. Exp Clin Transplant: Off J Middle East Soc Organ Transplant. 2016;14: 259-70.

8. Soubani AO, Pandya CM. The spectrum of noninfectious pulmonary complications following hematopoietic stem cell transplantation. Hematol/Oncol Stem Cell Ther. 2010;3:143-57.

9. Collaco JM, Gower WA, Mogayzel PJ Jr. Pulmonary dysfunction in pediatric hematopoietic stem cell transplant patients: overview, diagnostic considerations, and infectious complications. Pediatr Blood Cancer. 2007;49:117-26.

10. Huang TT, Hudson MM, Stokes DC, Krasin MJ, Spunt SL, Ness KK. Pulmonary outcomes in survivors of childhood cancer: a systematic review. Chest. 2011;140:881-901.

11. Skinner R, Kaplan R, Nathan PC. Renal and pulmonary late effects of cancer therapy. Semin Oncol. 2013;40:757-73.

12. Versluys AB, Bresters D. Pulmonary complications of childhood cancer treatment. Paediatr Respiratory Rev. 2016;17:63-70.

13. COG COG. Children's Oncology Group [COG] Long Term Follow-Up guidelines Version 5.0 2018. 2019. http://www. survivorshipguidelines.org/pdf/2018/COG_LTFU_Guidelines_ v5.pdf.

14. Sano H, Kobayashi R, Iguchi A, Suzuki D, Kishimoto K, Yasuda $\mathrm{K}$, et al. Risk factor analysis of idiopathic pneumonia syndrome 
after allogeneic hematopoietic SCT in children. Bone Marrow Transplant. 2014;49:38-41.

15. Hildebrandt GC, Fazekas T, Lawitschka A, Bertz H, Greinix H, Halter J, et al. Diagnosis and treatment of pulmonary chronic GVHD: report from the consensus conference on clinical practice in chronic GVHD. Bone Marrow Transplant. 2011;46:1283.

16. Yoshihara S, Yanik G, Cooke KR, Mineishi S. Bronchiolitis obliterans syndrome (BOS), bronchiolitis obliterans organizing pneumonia (BOOP), and other late-onset noninfectious pulmonary complications following allogeneic hematopoietic stem cell transplantation. Biol Blood Marrow Transplant. 2007;13:749-59.

17. Fidler MM, Reulen RC, Bright CJ, Henson KE, Kelly JS, Jenney $\mathrm{M}$, et al. Respiratory mortality of childhood, adolescent and young adult cancer survivors. Thorax. 2018;73:959-68.

18. Reulen RC, Winter DL, Frobisher C, Lancashire ER, Stiller CA, Jenney ME, et al. Long-term cause-specific mortality among survivors of childhood cancer. Jama. 2010;304:172-9.

19. Kirchhoff AC, Fluchel MN, Wright J, Ying J, Sweeney C, Bodson $\mathrm{J}$, et al. Risk of hospitalization for survivors of childhood and adolescent cancer. Cancer epidemiology, biomarkers \& prevention: a publication of the American Association for Cancer Research, cosponsored by the American Society of Preventive. Oncology. 2014;23:1280-9.

20. Kasteler R, Weiss A, Schindler M, Sommer G, Latzin P, von der Weid NX, et al. Long-term pulmonary disease among Swiss childhood cancer survivors. Pediatric Blood Cancer. 2018;65.

21. Dietz AC, Chen Y, Yasui Y, Ness KK, Hagood JS, Chow EJ, et al. Risk and impact of pulmonary complications in survivors of childhood cancer: A report from the Childhood Cancer Survivor Study. Cancer. 2016;122:3687-96.

22. Fanfulla F, Locatelli F, Zoia MC, Giorgiani G, Bonetti F, Spagnolatti L, et al. Pulmonary complications and respiratory function changes after bone marrow transplantation in children. Eur Respiratory J. 1997;10:2301-6.

23. Wieringa J, van Kralingen KW, Sont JK, Bresters D. Pulmonary function impairment in children following hematopoietic stem cell transplantation. Pediatr Blood Cancer. 2005;45:318-23.

24. Kuehni CE, Rueegg CS, Michel G, Rebholz CE, Strippoli MP, Niggli FK, et al. Cohort profile: the Swiss childhood cancer survivor study. Int J Epidemiol. 2012;41:1553-64.

25. Michel G, von der Weid NX, Zwahlen M, Adam M, Rebholz CE, Kuehni CE. The Swiss childhood cancer registry: rationale, organisation and results for the years 2001-2005. Swiss Med Wkly. 2007;137:502-9.

26. Mertens AC, Yasui Y, Liu Y, Stovall M, Hutchinson R, Ginsberg $\mathrm{J}$, et al. Pulmonary complications in survivors of childhood and adolescent cancer. A report from the Childhood Cancer Survivor Study. Cancer 2002;95:2431-41.

27. Green DM, Nolan VG, Goodman PJ, Whitton JA, Srivastava D, Leisenring WM, et al. The cyclophosphamide equivalent dose as an approach for quantifying alkylating agent exposure: a report from the Childhood Cancer Survivor Study. Pediatr Blood Cancer. 2014;61:53-67.

28. Ciurea SO, Andersson BS. Busulfan in hematopoietic stem cell transplantation. Biol Blood Marrow Transplant 2009;15:523-36.

29. Fleischhauer K. Selection of matched unrelated donors moving forward: from HLA allele counting to functional matching. Hematol Am Soc Hematol Educ Program. 2019;2019:532-8.

30. Eyrich M, Schulze H. HLA Matching in Pediatric Stem Cell Transplantation. Transfus Med hemotherapy: offizielles Organ der Dtsch Ges fur Transfusionsmedizin und Immunhamatologie. 2019;46:348-55.

31. Steliarova-Foucher E, Stiller C, Lacour B, Kaatsch P. International classification of childhood cancer, third edition. Cancer. 2005; 103:1457-67.
32. Software S STATA manual: nptrend [22.04.2020]. https://www. stata.com/manuals13/rnptrend.pdf.

33. Willasch AM, Peters C, Sedlacek P, Dalle JH, Kitra-Roussou V, Yesilipek A, et al. Myeloablative conditioning for allo-HSCT in pediatric ALL: FTBI or chemotherapy?-A multicenter EBMTPDWP study. Bone Marrow Transplant. 2020;55:1540-51.

34. Eapen M, Horowitz MM, Klein JP, Champlin RE, Loberiza FR Jr, Ringden $\mathrm{O}$, et al. Higher mortality after allogeneic peripheralblood transplantation compared with bone marrow in children and adolescents: the Histocompatibility and Alternate Stem Cell Source Working Committee of the International Bone Marrow Transplant Registry. J Clin Oncol. 2004;22:4872-80.

35. Simonin M, Dalissier A, Labopin M, Willasch A, Zecca M, Mouhab A, et al. More chronic GvHD and non-relapse mortality after peripheral blood stem cell compared with bone marrow in hematopoietic transplantation for paediatric acute lymphoblastic leukemia: a retrospective study on behalf of the EBMT Paediatric Diseases Working Party. Bone Marrow Transplant. 2017;52: 1071-3.

36. Pulsipher MA, Levine JE, Hayashi RJ, Chan KW, Anderson P, Duerst R, et al. Safety and efficacy of allogeneic PBSC collection in normal pediatric donors: the pediatric blood and marrow transplant consortium experience (PBMTC) 1996-2003. Bone Marrow Transplant. 2005;35:361-7.

37. Nysom K, Holm K, Olsen JH, Hertz H, Hesse B. Pulmonary function after treatment for acute lymphoblastic leukaemia in childhood. Br J Cancer. 1998;78:21-7.

38. Venkatramani R, Kamath S, Wong K, Olch AJ, Malvar J, Sposto $\mathrm{R}$, et al. Pulmonary outcomes in patients with Hodgkin lymphoma treated with involved field radiation. Pediatr Blood Cancer. 2014; 61:1277-81.

39. Inaba H, Yang J, Pan J, Stokes DC, Krasin MJ, Srinivasan A, et al. Pulmonary dysfunction in survivors of childhood hematologic malignancies after allogeneic hematopoietic stem cell transplantation. Cancer. 2010;116:2020-30.

40. Ginsberg JP, Aplenc R, McDonough J, Bethel J, Doyle J, Weiner DJ. Pre-transplant lung function is predictive of survival following pediatric bone marrow transplantation. Pediatr Blood Cancer. 2010;54:454-60.

41. Leung W, Ahn H, Rose SR, Phipps S, Smith T, Gan K, et al. A prospective cohort study of late sequelae of pediatric allogeneic hematopoietic stem cell transplantation. Medicine. 2007;86:215-24.

42. Madanat-Harjuoja LM, Valjento S, Vettenranta K, Kajosaari M, Dyba T, Taskinen M. Pulmonary function following allogeneic stem cell transplantation in childhood: a retrospective cohort study of 51 patients. Pediatr Transplant. 2014;18:617-24.

43. Uderzo C, Pillon M, Corti P, Tridello G, Tana F, Zintl F, et al. Impact of cumulative anthracycline dose, preparative regimen and chronic graft-versus-host disease on pulmonary and cardiac function in children 5 years after allogeneic hematopoietic stem cell transplantation: a prospective evaluation on behalf of the EBMT Pediatric Diseases and Late Effects Working Parties. Bone Marrow Transplant. 2007;39:667-75.

44. Hoffmeister PA, Madtes DK, Storer BE, Sanders JE. Pulmonary function in long-term survivors of pediatric hematopoietic cell transplantation. Pediatr Blood Cancer. 2006;47:594-606.

45. Louie AD, Robison LL, Bogue M, Hyde S, Forman SJ, Bhatia S. Validation of self-reported complications by bone marrow transplantation survivors. Bone Marrow Transplant. 2000;25:1191-6.

46. Kaya Z, Weiner DJ, Yilmaz D, Rowan J, Goyal RK. Lung function, pulmonary complications, and mortality after allogeneic blood and marrow transplantation in children. Biol Blood Marrow Transplant. 2009;15:817-26.

47. Chow EJ, Anderson L, Baker KS, Bhatia S, Guilcher GMT, Huang JT, et al. Late effects surveillance recommendations among survivors of childhood hematopoietic cell transplantation: a 
Children's Oncology Group Report. Biol Blood Marrow Transplant 2016;22:782-95.

48. Dietz AC, Duncan CN, Alter BP, Bresters D, Cowan MJ, Notarangelo L, et al. The second pediatric blood and marrow transplant consortium international consensus conference on late effects after pediatric hematopoietic cell transplantation: defining the unique late effects of children undergoing hematopoietic cell transplantation for immune deficiencies, inherited marrow failure disorders, and hemoglobinopathies. Biol Blood Marrow Transplant. 2017;23:24-9.

49. Shenoy S, Gaziev J, Angelucci E, King A, Bhatia M, Smith A, et al. Late effects screening guidelines after hematopoietic cell transplantation (HCT) for hemoglobinopathy: consensus statement from the second pediatric blood and marrow transplant consortium international conference on late effects after pediatric HCT. Biol Blood Marrow Transplant. 2018;24:1313-21. 